\title{
History of psychosurgery at Sainte-Anne Hospital, Paris, France, through translational interactions between psychiatrists and neurosurgeons
}

\author{
*Marc Zanello, MD, MSc, ${ }^{1,2,6}$ Johan Pallud, MD, PhD, ${ }^{1,2,6}$ Nicolas Baup, MD, PhD, ${ }^{3}$ \\ Sophie Peeters, MSc, ${ }^{1}$ Baris Turak, MD, ${ }^{1,6}$ Marie Odile Krebs, MD, PhD, $, 4,4,6$ \\ Catherine Oppenheim, MD, PhD, ${ }^{2,5,6}$ Raphael Gaillard, MD, PhD, ,3,46 and Bertrand Devaux, MD 1,6
}

${ }^{1}$ Neurosurgery Department, ${ }^{3}$ Department of Psychiatry, Service Hospitalo-Universitaire, and ${ }^{5}$ Neuroradiology Department, Sainte-Anne Hospital; ${ }^{2}$ IMABRAIN, INSERM U894, and ${ }^{4}$ Laboratoire de Physiopathologie des Maladies Psychiatriques, Centre de Psychiatrie et Neurosciences, UMR S894; and ${ }^{6}$ University Paris Descartes, Paris, France

Sainte-Anne Hospital is the largest psychiatric hospital in Paris. Its long and fascinating history began in the 18th century. In 1952, it was at Sainte-Anne Hospital that Jean Delay and Pierre Deniker used the first neuroleptic, chlorpromazine, to cure psychiatric patients, putting an end to the expansion of psychosurgery. The Department of Neuro-psychosurgery was created in 1941. The works of successive heads of the Neurosurgery Department at Sainte-Anne Hospital summarized the history of psychosurgery in France.

Pierre Puech defined psychosurgery as the necessary cooperation between neurosurgeons and psychiatrists to treat the conditions causing psychiatric symptoms, from brain tumors to mental health disorders. He reported the results of his series of 369 cases and underlined the necessity for proper follow-up and postoperative re-education, illustrating the relative caution of French neurosurgeons concerning psychosurgery.

Marcel David and his assistants tried to follow their patients closely postoperatively; this resulted in numerous publications with significant follow-up and conclusions. As early as 1955, David reported intellectual degradation 2 years after prefrontal leucotomies.

Jean Talairach, a psychiatrist who eventually trained as a neurosurgeon, was the first to describe anterior capsulotomy in 1949. He operated in several hospitals outside of Paris, including the Sarthe Psychiatric Hospital and the Public Institution of Mental Health in the Lille region. He developed stereotactic surgery, notably stereo-electroencephalography, for epilepsy surgery but also to treat psychiatric patients using stereotactic lesioning with radiofrequency ablation or radioactive seeds of yttrium- 90 .

The evolution of functional neurosurgery has been marked by the development of deep brain stimulation, in particular for obsessive-compulsive disorder, replacing the former lesional stereotactic procedures.

The history of Sainte-Anne Hospital's Neurosurgery Department sheds light on the initiation-yet fast reconsiderationof psychosurgery in France. This relatively more prudent attitude toward the practice of psychosurgery compared with other countries was probably due to the historically strong collaboration between psychiatrists and neurosurgeons in France.

https://thejns.org/doi/abs/10.3171/2017.6.FOCUS17250

KEY WORDS psychosurgery; history; interdisciplinary studies; neuropsychology; ethics

$\mathrm{T}$ $\checkmark$ HE treatment of psychiatric patients by means of surgical interventions is an ancient idea. Attempts to cure psychiatric patients through surgical approaches have existed since prehistory. ${ }^{52}$ Nevertheless, the term psychosurgery refers to a more recent period, beginning with the work of a Portuguese neurologist, Egas Moniz, in the 1930s. Moniz was a brilliant person. After training in neurology in France, he became involved in politics and held different political positions, including minister of foreign affairs of Portugal. He eventually returned to

ABBREVIATIONS OCD = obsessive-compulsive disorder; WWII = World War II.

SUBMITTED April 30, 2017. ACCEPTED June 27, 2017.

INCLUDE WHEN CITING DOI: 10.3171/2017.6.FOCUS17250.

* Drs. Gaillard and Devaux contributed equally to this work. 


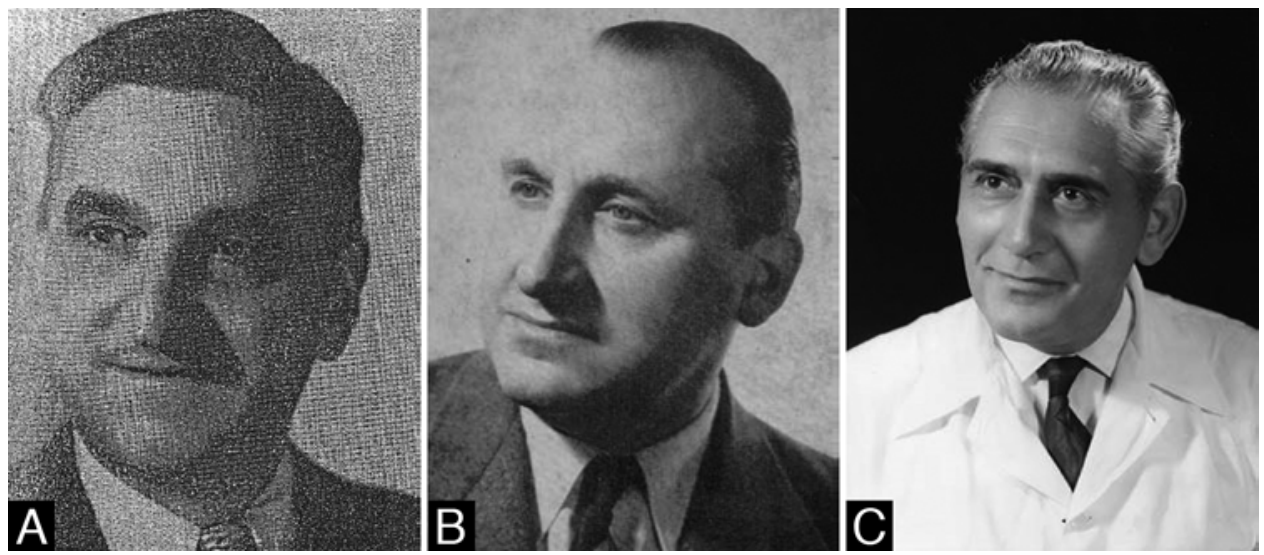

FIG. 1. Pictures of Pierre Puech (A), Marcel David (B), and Jean Talairach (C). Reproduced with permission from Brunon J: Histoire de la Neurochirurgie Francophone, Regimedia Edition, 2008.

medicine and developed cerebral angiography in 1927. He attended the Second Neurological Congress in London in 1935, where he was impressed with the work of Clovis Vincent on frontal lobe tumors and with that of John Fulton and Carlyle Jacobsen on behavioral changes induced by surgical lesions in the frontal lobes of 2 primates. ${ }^{39,51}$

Six months later, Egas Moniz, with the help of a neurosurgeon, Almeida Lima, began performing the first prefrontal leucotomies in human patients. It was in Paris, in 1936, that Egas Moniz presented and published his first book on this topic, entitled Tentatives Opératoires dans le Traitement de Certaines Psychoses (Operative Attempts in Treating Certain Psychoses). ${ }^{34}$ His work aroused interest among the medical community and in particular of Walter Freeman, a neuropsychiatrist at George Washington University (Washington, DC). The proselytism of Walter Freeman ensured the initial success of psychosurgery, in part due to the difficult time for American psychiatry. However, his associate neurosurgeon, John Watts, who initially worked with Walter Freeman, refused to follow the fast-growing indications for surgery in psychiatric patients. ${ }^{42}$ Walter Freeman decided to operate alone, without any neurosurgical formation. He reproduced the transorbital lobotomy, a simple technique described by Amarro Fiamberti, an Italian psychiatrist, and operated on thousands of patients throughout the United States. ${ }^{42}$

Sainte-Anne Hospital (Paris, France) was founded in 1651 , initially as an asylum for psychiatric patients, and became a hospital in 1772. In 1952, the psychiatrists Jean Delay and Pierre Deniker from Sainte-Anne Hospital reported preliminary positive results in the treatment of psychosis with chlorpromazine, the first neuroleptic drug. ${ }^{18}$ Sainte-Anne Hospital benefited from a clinic of general surgery dedicated to psychiatric patients between 1892 and 2005. ${ }^{11}$ This General Surgery Department did not perform new surgical procedures or neurosurgery. The Neurosurgery Department of Sainte-Anne Hospital was created in 1941 thanks to Pierre Puech, a pioneer of French neurosurgery. Interestingly, the Neurosurgery Department was, at first, entitled the Neuro-psychosurgery Department. It was initially devoted to investigating the role of surgery in curing psychiatric illnesses.
The aim of the present study is to shed light on the history of interactions between psychiatry and neurosurgery that permitted the development of psychosurgery at Sainte-Anne Hospital, beginning with the creation of the department until ongoing clinical trials.

\section{Historical Attempts at Psychosurgery}

Figure 1 presents the portraits of Pierre Puech, Marcel David, and Jean Talairach.

\section{Pierre Puech (1897-1950)}

Pierre Puech met Clovis Vincent, one of the first 2 French neurosurgeons with Thierry De Martel, during World War I. He went to the United States in 1930 with Vincent and Marcel David, another student of Vincent's, to learn from the first neurosurgeons: Percival Bailey, Harvey Cushing, and William Peet. Just before World War II (WWII), Puech had a disagreement with Vincent and left the Neurosurgical Department of Pitié Hospital, which was headed by Vincent. ${ }^{9}$ Puech initiated the neurosurgical activity at Sainte-Anne Hospital in 1939, and the Department of Neurosurgery was officially created in 1941. Nevertheless, French psychiatrists had some doubts concerning psychosurgery, favoring shock therapies, and psychosurgery remained confidential before WWII in France.

In 1941, Puech wrote an article entitled "De l'intérêt d'une liaison entre neuro-psychiatrie et neurochirurgie," in which he discussed the necessary cooperation among neurologists, psychiatrists, and neurosurgeons ${ }^{40}$ with potential benefits for patients, society, and science. Puech noted that many patients who were hospitalized in psychiatric hospitals suffered from diseases that were amenable to efficient neurosurgical treatment. The psychiatric symptoms could reveal the following: 1) brain tumors, 2) meningeal and cerebral inflammatory lesions, 3) craniocerebral traumatisms, 4) epileptogenic lesions, and 5) mental syndrome of unknown etiology. He did not present any leucotomy cases..$^{40}$ In 1942, during a meeting of the Medico-Psychological French Society in Paris, Puech stated that "We will not insist on performing any interventions that are not proven to be beneficial (lobectomy, 
TABLE 1. Psychosurgery series at the Neurosurgery Department of Sainte-Anne Hospital from 1941 to May $1950^{41}$

\begin{tabular}{|c|c|c|c|c|c|c|c|}
\hline \multirow[b]{3}{*}{ Surgical Technique } & \multirow{3}{*}{$\begin{array}{l}\text { Deaths } \\
(\%)\end{array}$} & \multirow{3}{*}{$\begin{array}{c}\text { Postop } \\
\text { Epilepsy } \\
\text { (no.) }\end{array}$} & \multicolumn{5}{|c|}{ Results by Indication (\%) } \\
\hline & & & \multirow{2}{*}{$\begin{array}{l}\text { Obsessive } \\
\text { Neurosis }\end{array}$} & \multirow[b]{2}{*}{ Depression } & \multicolumn{3}{|c|}{ Schizophrenia } \\
\hline & & & & & Paranoid & Catatonic & Disorganized \\
\hline \multicolumn{8}{|l|}{ Standard prefrontal lobotomy $(n=223)^{*}$} \\
\hline Good $\dagger$ & \multirow{3}{*}{3.0} & \multirow{3}{*}{3} & 50 & 48 & 25 & 20 & - \\
\hline Relative improvement† & & & $15 \ddagger$ & 15 & 15 & 15 & - \\
\hline Bad† & & & $35 \ddagger$ & 37 & 60 & 65 & - \\
\hline Transorbital prefrontal lobotomy $(n=35)$ & 2.9 & - & & & Poor & & \\
\hline \multicolumn{8}{|l|}{ Topectomy $(\mathrm{n}=79$ ) } \\
\hline Good $†$ & & & 40 & 0 & 25 & 25 & 0 \\
\hline Relative improvement† & 3.8 & 3 & - & 0 & 15 & 15 & 0 \\
\hline Bad† & & & - & 100 & 60 & 60 & 100 \\
\hline Focal disconnection $(n=24)$ & - & - & \multicolumn{5}{|c|}{ Lack of follow-up } \\
\hline Thalamotomy $(n=8)$ & - & - & \multicolumn{5}{|c|}{$\begin{array}{l}1 \text { case of severe parkinsonian syndrome, } 3 \text { cases of mental } \\
\text { retardation, } 4 \text { cases of irreducible pain }\end{array}$} \\
\hline
\end{tabular}

prefrontal leucotomy)."10 This rather unusual definition of psychosurgery and the interdisciplinary collaboration desired by Puech represented a new and quite modern way of thinking.

After WWII, psychosurgery developed rapidly, especially in English-speaking countries. The promising results (e.g., during the First International Conference on Psychosurgery [Lisbon, Portugal] in $1948^{22}$ and the Nobel Prize awarded to Edgar Moniz in 1949 for "the discovery of leucotomy as treatment in certain psychoses") sped up the diffusion of psychosurgery. ${ }^{35}$ In parallel, French neurosurgery continued to grow with the appointment of the first neurosurgeons in Paris at Sainte-Anne and Pitié Hospitals: David, Puech, Jean Guillaume, and Jacques Le Beau. The simultaneous expansion of both psychosurgery and neurosurgery in France explained the rise of psychosurgery in the country between 1945 and 1955.

Puech had planned to summarize his experience with psychosurgery. However, he died suddenly in 1950 at the age of 47 years, 48 hours after an acute myocardial infarction that he diagnosed himself. ${ }^{9}$ His assistants, Drs. Guilly and Lairy-Bounes, wrote the Introduction à la Psychochirurgie (Introduction to Psychosurgery) in his memory. ${ }^{41}$ Table 1 summarizes the results reported in this book. Figures 2 and 3 were originally published in the book and illustrate the surgical techniques used by Puech and his assistants.

This 153-page book is divided into 2 sections: the first addresses the etiologies of "lesional psychosurgery," namely the organic ones related to psychiatric disorders. The authors described brain tumors, craniocerebral trauma, and disorders of CSF responsible for secondary psychiatric illness. The second section, which addresses "functional psychosurgery," describes the methods and results of what is now called psychosurgery. The functional psychosurgery section is divided into 4 subsections devoted to the 4 surgi- cal techniques used, which include: 1) leucotomies, namely prefrontal lobotomies through burr holes (Fig. 2); 2) topectomies, namely bilateral cortical resection of Brodmann areas 9 and 10;3) lobectomies; and 4) thalamotomies, namely partial resection of the thalamus.

Authors claimed that surgery remained a last-resort treatment and should always be preceded by maximal medical therapy, including electroconvulsive therapy, Sakel therapy (at least 30 sessions but routinely up to 60 sessions of large doses of repeated insulin injections to produce daily comas), and psychoanalysis. Another strong message was that psychiatrists were responsible for the operative indication. Among the patients operated on after psychiatric agreement, Puech found excellent results, but $>90 \%$ of cases were not successful when surgery was proposed upon the family's request. There were no real contraindications to leucotomies. Age, in particular, was not a limiting factor-the patient age range in Sainte-Anne's series was 9-76 years, with "good results" for both extremes.

Puech criticized the transorbital leucotomy. This blind technique was not safe enough, in his opinion, and he ceased using it after a patient died due to intracerebral hemorrhage. The authors took into account the rising criticism of psychosurgery, acknowledging that many patients, especially those who lived far from Paris, were lost to follow-up and that results decreased with time. Schizophrenia was the disease with the worst results, whereas the best results were obtained in depression.

Introduction à la Psycho-chirurgie reflects the willingness of Puech and his assistants to investigate psychiatric illness in detail. The book discusses results of preoperative electroencephalography, intraoperative electrocorticography (Fig. 3), and pathological examinations. Anatomopathology was one of the main arguments of Pierre Puech's team in support of psychosurgery: $72 \%$ of patients had abnormal brain tissue. The authors stated that the shock 


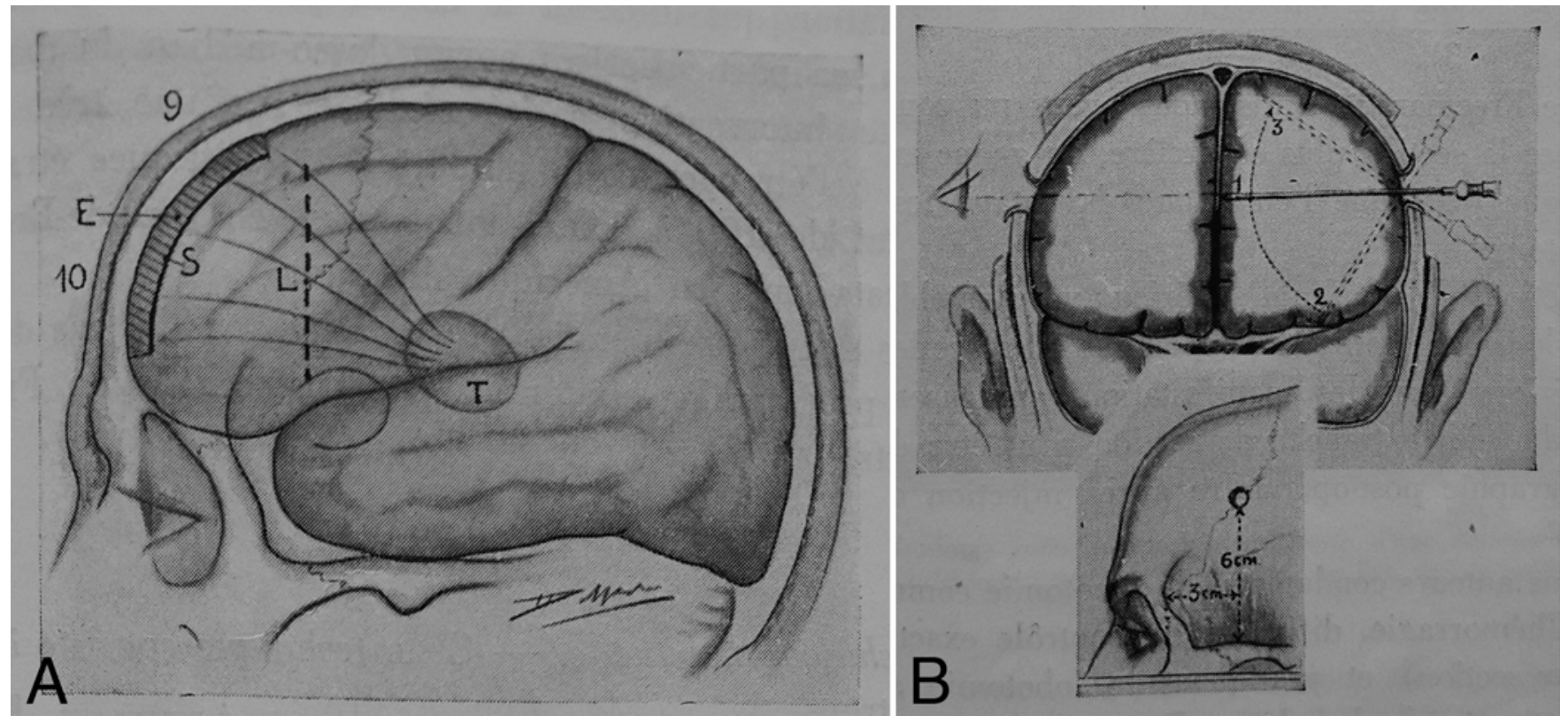

FIG. 2. A: Sagittal representation of the 4 different surgical techniques used by Puech and his assistants to perform psychosurgery. $E=$ prefrontal cortical resection (topectomy); $S=$ subcortical section; $L=$ prefrontal lobotomy; $T=$ thalamotomy; 9 and 10 $=$ Brodmann areas 9 and 10. B: Detailed description of prefrontal lobotomy. Upper: Coronal representation of the 2 burr holes and the leucotome movement (1,2, then 3). Lower: Sagittal representation of the bony landmarks used to make the 2 burr holes. Reproduced with permission from Puech et al: Introduction à la Psycho-chirurgie, Masson, 1950.

therapies delivered to the patients probably explained this high proportion of abnormal examination findings. They also emphasized the importance of postoperative rehabilitation and follow-up.

\section{Marcel David (1898-1986)}

After the death of Puech, the management of SainteAnne Hospital's Neurosurgery Department was entrusted to Marcel David. As stated above, David was another assistant of Clovis Vincent during the 1928-1939 period. In 1939, he left the Neurosurgical Department of the Pitié Hospital, in solidarity with Puech. After WWII and the armistice, he worked at several hospitals, mainly Paul Brousse Hospital, and constituted a team with Henri Hécaen, Julian de Ajuriaguerra, and Jean Talairach. David and his assistants joined Puech's remaining assistants, forming a new team that represented the Neurosurgery Department of Sainte-Anne Hospital.

David performed the first leucotomies in Professor Claude's department at Sainte-Anne Hospital under the supervision of Moniz himself in 1936; however, these first attempts "had not been a success and were not published."17,41 David remained interested in psychosurgery. In 1949, shortly before arriving at Sainte-Anne Hospital, David and Talairach published their series of 137 prefrontal lobotomies. Only the 7\% mortality rate was disclosed because they "let (their) psychiatry colleagues (...) analyze the therapeutic results." 17 Nevertheless, they described their procedure, which consisted of operating with the patient in a seated position under local anesthesia with a surgeon on each side. They did not mention any absolute contraindication to the procedure. David and Talairach believed that such surgical procedures could be done in psychiatric departments on the condition that adequate surgical equipment was available. This statement was indeed carried out in practice. ${ }^{17}$

In France, the operations were almost entirely performed by neurosurgeons, and if patients went to SainteAnne Hospital to be operated on by Puech, it was less costly and easier to bring a surgical team into psychiatric hospitals than to move patients suffering from serious psychiatric diseases. For instance, starting in July 1949, the neurosurgical team at Sainte-Anne Hospital visited the Sarthe Psychiatric Hospital (Le Mans, France). Between July 1949 and March 1954, 82 female patients were operated on by David and Talairach.

This series was reported by Louis Anglade, chief psychiatrist of the Sarthe Psychiatric Hospital. He insisted again on the restricted indications for psychosurgery-that it only be done after maximal attempt at medical treatment and failure thereof, be performed by "trained technicians," and include a necessary intense postoperative re-education. Nevertheless, with all of these conditions satisfied, beneficial results represented $70 \%$ of the cohort. The definition of "promising" results remained vague, ranging from improved adaptation to the psychiatric hospital environment to complete remission with return to work.

The critiques made by psychiatrists on this topic exposed the increase in doubts about psychosurgery in the psychiatric community. ${ }^{2}$ In 1955 , the number of lobotomies performed had decreased by half, probably affected by increased availability of neuroleptic agents and a change in perception of such surgical procedures, without being entirely insignificant ( $>5$ lobotomies per year). The last pa- 

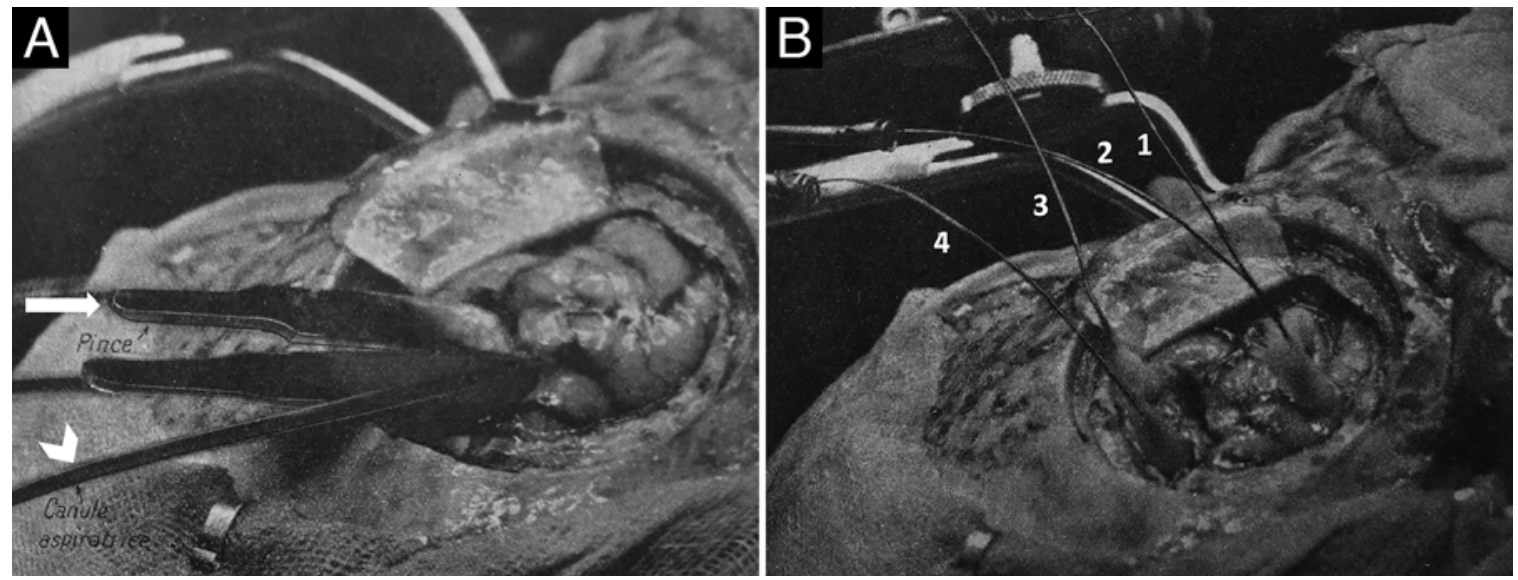

FIG. 3. A: Subcortical section using a clamp (arrow) and a suction cannula (arrowhead). B: Intraoperative electrocorticography using 4 electrodes. Reproduced with permission from Puech et al: Introduction à la Psycho-chirurgie, Masson, 1950.

tient was operated on in $1967 .{ }^{23}$ David and Talairach worked in other provincial hospitals, including those at Fleury les Aubrais, Bonneval, Clermont-Ferrand, and Nancy. ${ }^{25}$ Local multidisciplinary teams that brought together neurosurgeons, psychiatrists, and psychologists were gradually forming. After 1970, there was no longer any evidence of such interventions outside of Sainte-Anne Hospital.

The neurosurgeons' dedication to following their patients so closely should explain, at least in part, the questioning of psychosurgery that surfaced in France around the 1950s due to poor results that arose several months after the operation. In 1953, David and his assistants published their results obtained from 78 patients at the 12-month follow-up: 14 patients (18\%) showed significant improvement, with disappearance of symptoms and return to normal social life; 13 patients (16\%) had improved, defined as a reduction of symptoms and better familial or hospital life; 10 patients (14\%) demonstrated symptomatic remission corresponding to either a transient disappearance or reduction of symptoms; and 41 patients (52\%) did not exhibit any postoperative improvement.

These poor results, compared with previous publications, underlined the need for close and long-term followup of postoperative psychiatric patients. ${ }^{16}$ However, this remained a difficult task, as stated in an article published in 1955: Of 100 patients who benefited from a neuropsychological preoperative examination, only approximately 40 patients were examined at 6 months, 26 at 1 year, and 15 at 2 years. At 2 years, patients with good postoperative results presented with a slight neurological defect compared with their preoperative evaluation. ${ }^{15}$

David returned to the Pitie Hospital in 1960 to fill the Head of the Neurosurgery Department position and retired in 1969. ${ }^{24}$

\section{Jean Talairach (1911-2007)}

Jean Talairach was studying psychiatry at the beginning of his medical career. In 1940, he became consultant psychiatrist in the "Clinique des Maladies Mentales et de l'Encéphale," the Psychiatry Department of Professor Jean Delay. He quickly became interested in the thera- peutic possibilities of neurosurgery. He is quoted as saying, "Psychosurgery is too important to be left to neurosurgeons alone." $"$ As early as 1942, he was awarded the Forque-Baumetz Prize by the Académie de Chirurgie for the stereotactic tracking of subcortical regions. ${ }^{30,44} \mathrm{He}$ met Marcel David at the Val de Grâce Military Hospital at the end of WWII and followed him to Paul Brousse Hospital. David encouraged him to pursue his works concerning stereotaxy and convinced Talairach to change his focus from psychiatry to neurosurgery. ${ }^{30} \mathrm{He}$ was trained from 1946 to 1952 by David. Talairach focused on epilepsy surgery and developed stereo-electroencephalography. ${ }^{12}$

Talairach kept in touch with his psychiatry colleagues from his initial career. As mentioned earlier, he joined David on a tour to different provincial hospitals and continued after David's departure, ending at the Sarthe Psychiatric Hospital. ${ }^{23}$ Talairach eventually also visited the Lille region's Public Institution of Mental Health (Lommelet, France) to perform psychosurgery procedures. ${ }^{1}$ The tight regulation on psychosurgery resulted in scant lobotomies being performed by psychiatrists in France. Apart from the first description of a prefrontal leucotomy done in France in 1940 by Gaston Ferdière, and Pierre Menger's work entitled "A prefrontal intervention available only to the psychiatrist" in 1954, no psychiatrist reported having performed psychosurgical procedures. ${ }^{20,31}$

The negative criticism sprouting from the 2 aforementioned works underlined the clear distinction between surgery and psychiatry that existed in France..$^{19}$ Making this clear distinction between a surgical action and an evaluation facilitated the reconsideration of psychosurgery in France. ${ }^{4,5}$ Between 1946 and 1949, in the Neurosurgery Department managed by David at Paul Brousse Hospital, Talairach performed 137 prefrontal lobotomies. However, his initial training as a psychiatrist, combined with his scientific rigor, led him to favor selective approaches when he definitely moved to Sainte-Anne Hospital and developed his stereotactic methodology. Talairach was the first to describe the anterior capsulotomy, a selective procedure of stereotactic thermocoagulations of thalamo-frontal fibers arising from the anterior capsule. ${ }^{45} \mathrm{He}$ also performed ste- 

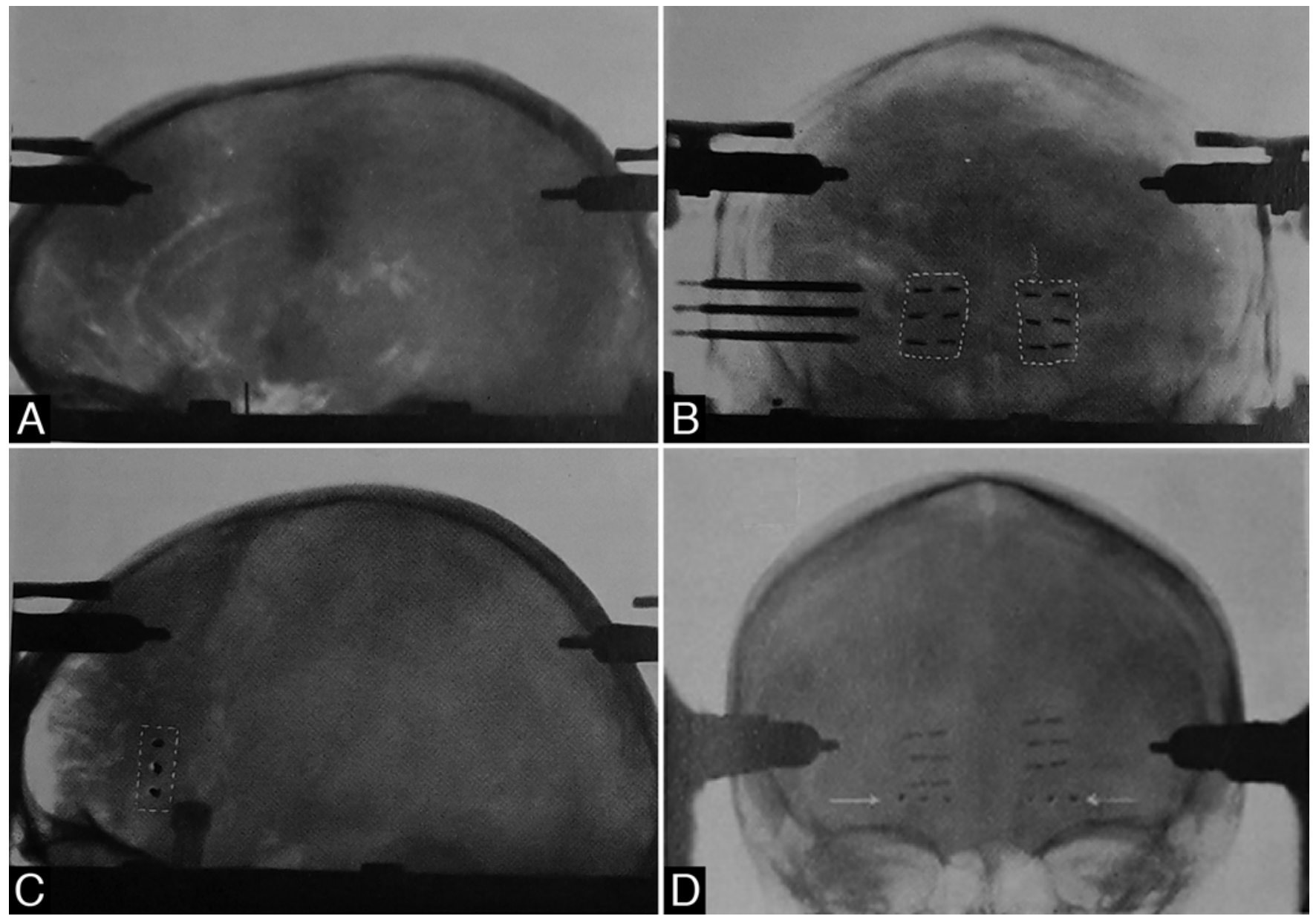

FIG. 4. Stereotactic psychosurgical intervention. A: Encephalography revealing the anterior cingulate cortex. B: Frontal radiograph showing the implantation of radioactive seeds of yttrium- 90 through needles guided by stereotaxy. Seeds of yttrium- 90 emitted Beta decay and damaged a cerebral zone of approximatively $70 \mathrm{~mm}^{3}$ (dotted line). C: Lateral radiograph showing the implantation of radioactive seeds of yttrium-90 with a good correlation between right and left sides (overlapping of the radioactive seeds). D: Reoperation with enlargement of anterior cingulate cortex lesioning to the internal orbital part of the frontal lobes. Reproduced with permission from Talairach J, Morel P: Encycl Méd Chir 37-830-A:10-17, 1963.

reotactic thermocoagulations of the anterior ventral nucleus of the thalamus. ${ }^{17}$

Between 1950 and 1960, the development of psychopharmacology and the obviously disappointing results of numerous psychosurgical interventions changed both medical and general opinions on the matter..$^{32}$ Fewer and fewer patients were operated on, and the indications were more limited. However, psychosurgery remained an acceptable treatment for a few selected patients. The tone of the article written by Talairach in 1963 summarized the feeling of French neurosurgeons:

Psychosurgery, after a period of significant expansion around 1950, seems to have a much reduced role nowadays. This decline is mainly related to the development of psychopharmacology. Like every functional surgery intervention, it is apparent that psychosurgery is a last resort and should be offered only after failure of all other therapeutic options.

However, there is no doubt that psychosurgery can offer successful and permanent therapeutic results. ${ }^{46}$

In this review, Talairach outlined his approach to psychosurgery. He recommended stereotactic lesioning based on the following: 1) better anatomical positioning than classic bony landmarks, 2) reduced perioperative risks, 3) use of radiological landmarks thanks to pneumoencephalography, and 4) the possibility of stereo-electroencephalography. ${ }^{46}$

Although he no longer used thermocoagulation, Talairach implanted radioactive seeds of yttrium-90 with a 2-mm needle. The target area could be enlarged during a second intervention if clinically indicated. Figure 4 illustrates a representative case. Two contraindications to stereotactic lesioning were quoted in this article: chronic kidney disease and cerebral atrophy. Talairach reported no deaths or postoperative complications after 40 cases of yttrium-90 seed stereotactic implantation. ${ }^{46}$ Despite reporting precise results, he stated that a good result was observed in one-third of patients, average results in onethird, and poor results in another one-third.

At the end of the 1960s, 3 main factors explained a timid reintroduction of psychosurgery: 1 ) the relative stagnation of psychopharmacology, 2) the side effects of the psychotropic drugs, and 3) the development of stereotactic 
neurosurgery. ${ }^{33}$ In August 1970, the Second International Conference on Psychosurgery took place in Copenhagen. The Tuskegee syphilis experiment scandal in 1972 led to the striking evolution of biomedical research in the United States with the creation of the National Commission for the Protection of Human Subjects of Biomedical and Behavioral Research in 1974. ${ }^{38}$ The Commission issued a report and recommendations in 1977 regarding psychosurgery. Interestingly, and contrary to popular opinion, the Commission strongly regulated psychosurgery but did not ban it:

The Commission finds that there is at least tentative evidence that some forms of psychosurgery can be of significant therapeutic value in the treatment of certain disorders or in the relief of certain symptoms. Because of this finding and the belief that the misuse of psychosurgery can be prevented by appropriate safeguards, the Commission has not recommended a ban on psychosurgery. ${ }^{14,43}$

This "second wave of psychosurgery" led to an updated article on French psychosurgery by Talairach and other established French neurosurgeons such as Jacques Le Beau, author of a monograph on psychosurgery. ${ }^{27} \mathrm{Ta}-$ lairach remained very careful concerning the indications for psychosurgery: only after refractory maximal medical management and for obsessive-compulsive disorder (OCD) cases. The yearly census of psychosurgery patients at Sainte-Anne Hospital ranged from 2 to 3 patients. The authors concluded that extending the use of psychosurgery to treating "sexual deviance, delinquency, even some behavioral troubles" was unreasonable, unnecessary, and unethical. ${ }^{3}$ Jean Bancaud, a close collaborator of Talairach, criticized the return of psychosurgery in an October 1975 interview. ${ }^{25}$ These conclusions again highlighted the precautionary approach of Sainte-Anne Hospital's neurosurgical team toward psychosurgery. Nevertheless, approximately 20,000 patients endured psychosurgical interventions between 1946 and 1976 in France. ${ }^{25}$

Following David's departure, the Neurosurgery Department of Sainte-Anne Hospital was divided into 2 distinct departments: one of conventional neurosurgery and the other devoted to stereotactic and functional neurosurgery. ${ }^{44}$ Talairach became head of the latter department. Despite his retirement in 1980, he pursued his research and published his third and fourth stereotactic atlases in 1988 and 1993. ${ }^{47,48}$ He died at Sainte-Anne Hospital in March 2007, in a patient room that had been his office in the past. ${ }^{30}$

\section{Modern Times}

Alain Jaubert counted 23 French Neurosurgery Departments that had performed 300-350 psychosurgical interventions in $1976 .{ }^{25}$ Thus it seems that the practice of psychosurgery quickly declined in France. A report of the Inspection Générale des Affaires Sociales noted only 32 lobotomies in 7 of 72 French Neurosurgery Departments between 1980 and $1986 . .^{13}$

At Sainte-Anne Hospital, the last frontal lobotomies were performed by Jean-Paul Chodkiewicz, who became the head of the Stereotaxic Neurosurgical Department after Talairach's retirement in 1980. Using a technique of stereotactic multiple thermocoagulations, 3 patients suffering from severe OCD underwent a neurosurgical procedure between 1983 and 2001 performed by one of us
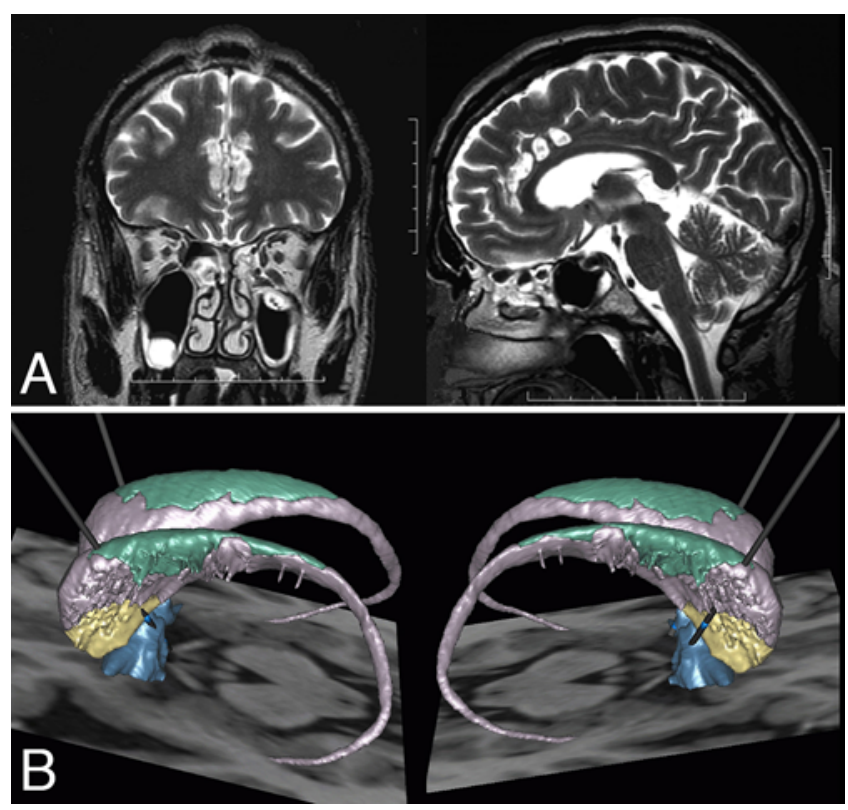

FIG. 5. A: Stereotactic bilateral anterior cingulotomy for resistant and disabling OCD: 6-month postoperative coronal T2-weighted MR image (left) and sagittal T2-weighted MR image (right). B: Deep brain stimulation targeting the nucleus accumbens for pharmacoresistant major depressive disorder. 3D postoperative sagittal reconstruction of the electrode placement into basal ganglia: left hemisphere (left) and right hemisphere (right).

(B.D.). ${ }^{34}$ They were the last patients operated on with a lesional technique at Sainte-Anne Hospital.

The promising results of deep brain stimulation performed in patients with Parkinson disease; the reversibility and modulation capabilities of this technique, offering greater efficacy and less morbidity to patients; and the initial results reported by Nuttin et al. using anterior capsule deep brain stimulation instead of thermal or Gamma Knife lesions in patients with $\mathrm{OCD}^{36}$ prompted the French National Consultative Ethics Committee to reconsider psychosurgery as a potential treatment option, with warnings about strict consent and efficacy evaluations, in 2002. ${ }^{13}$

OCD is essentially characterized by recurrent obsessive thoughts or compulsive acts. Pharmacoresistant, severe, and incapacitating OCD had been recognized as one of the better indications for psychosurgery: neurosurgical treatment could be deep brain stimulation or ablative neurosurgery. ${ }^{21,49}$ The Neurosurgery Department of Sainte-Anne Hospital proposed these therapeutic options for selected patients ${ }^{29,37}$ and is a member of the French Stimulation in the Trouble Obsessionnel Compulsif Study Group. 7,10,27,28,47,50

Treatment-refractory depression is a major cause of loss of life and productivity. Since 2005, numerous deep brain stimulation targets have been used to reduce signs and symptoms of pharmacoresistant major depressive disorder, including the subcallosal cingulate cortex, nucleus accumbens, and ventral capsule and ventral striatum. Further studies are now required to improve the efficacy of deep brain stimulation in depression. Of note, SainteAnne Hospital's multidisciplinary team participates in the 
STHYM (Deep Brain Stimulation in Patients With Chronic Treatment Resistant Depression) study (NCT01973478; ClinicalTrials.gov).

Figure 5 illustrates 2 cases treated at Sainte-Anne Hospital: 1 patient suffering from resistant and disabling OCD treated by ablative neurosurgery (Fig. 5A), and 1 patient suffering from pharmacoresistant major depression treated by deep brain stimulation (Fig. 5B).

\section{Perspectives}

Psychosurgery carries many misperceptions. In the general opinion, psychosurgery remains a desperate attempt to cure refractory psychiatric patients doomed to fail. In light of the history of Sainte-Anne Hospital's Neurosurgery Department, it seems that this oversimplified image should be qualified. Obviously, prefrontal leucotomies had been executed around the world without any rigorous medical evaluation, but the strong cooperation existing between psychiatrists and neurosurgeons in France limited possible abuses of the procedure as seen in other countries.

It was with the help and under the supervision of Henri Laborit, a French military surgeon, that Jean Delay and Pierre Deniker used chlorpromazine in $1952 .{ }^{26}$ Like the dual training of Talairach, this underlines the need for close collaboration between psychiatrists and neurosurgeons, to carefully select and follow the patients who are good candidates for psychosurgery while respecting all ethical and scientific restrictions. This remains the guideline for the future cooperation between functional neurosurgeons and psychiatrists involved in psychosurgery protocols at Sainte-Anne Hospital. Bearing in mind that neurosurgery is an evolving specialty and that investigational and surgical methods are undergoing continuous development and change, the 21st century may be the epoch of mature psychosurgery.

\section{Acknowledgments}

We thank Jacques Brunon, the Bibliothèque Interuniversitaire de Santé, and Editions Elsevier-Masson.

\section{References}

1. Alexandre JY: Lommelet. L'histoire continue 1825-2013. Lille, France: EPSM de l'agglomération lilloise, 2013 (http:// www.epsm-al.fr/sites/www.epsm-al.fr/files/publicationlommelet-1825-2013.pdf) [Accessed July 12, 2017]

2. Anglade L, Fraillon J, Fessard J, Maunoury P: Une expérience de cinq années de lobotomies à l'hôpital psychiatrique de la Sarthe; échechs et réadaptations sociales. Ann Med Psychol (Paris) 113:420-429, 1955

3. Bancaud J, Chodkiewicz JP, Choppy-Jacolin M, Gaches J, Issembert RP, Le Beau J, et al: Opérer la folie? Ou le retour de la psychochirurgie. Concours Méd 28-5:3659-3665, 1977

4. Baruk H: Des Hommes Comme Nous, Mémoires D’un Neuropsychiatre. Paris: Robert Laffont, 1976

5. Baruk H: Sur la nécessité de l'interdiction légale de la lobotomie. Ann Med Psychol 112:60-68, 1954

6. Benabid AL: Jean Talairach (1911-2007). Stereotact Funct Neurosurg 86:62-63, 2008

7. Bourredjem A, Pelissolo A, Rotge JY, Jaafari N, Machefaux S, Quentin S, et al: A video clinical global impression (CGI) in obsessive compulsive disorder. Psychiatry Res 186:117122,2011
8. Breggin P: The return of lobotomy and psychosurgery. Congr Rec 118:H1602-H1612, 1972

9. Brunon J: Histoire de la neurochirurgie francophone. Paris: Regimedia, 2008

10. Caire M: Histoire de la psychiatrie en France. (http:// psychiatrie.histoire.free.fr) [Accessed July 18, 2017]

11. Centre hospitalier Sainte-Anne: Historique. Centre hospitalier Sainte-Anne. (http://www.ch-sainte-anne.fr/ Etablissement/Historique) [Accessed July 14, 2017]

12. Chauvel P: Hommage à Jean Talairach (1911-2007). Epilepsies 20:77-80, 2008

13. Comité Consultatif National d'Ethique: La neurochirurgie fonctionnelle d'affections psychiatriques sévères. Paris: Comité Consultatif National d'Ethique pour les sciences de la vie et de la santé, 2002

14. Culliton BJ: Psychosurgery: National Commission issues surprisingly favorable report. Science 194:299-301, 1976

15. David M, Moor L: [Intellectual function of 15 patients 2 years after psychosurgery.] Ann Med Psychol (Paris) 113:416-420, $1955(\mathrm{Fr})$

16. David M, Sauguet J, Hecaen H, Talairach J: [Follow-up of 78 cases of psychosurgery a year after the operation.] Rev Neurol (Paris) 89:3-21, $1953(\mathrm{Fr})$

17. David M, Talairach J: Quelques réflexions sur les lobotomies préfrontales. Evol Psychiatr (Paris) 4:532-540, 1949

18. Delay J, Deniker P, Harl JM: [Therapeutic use in psychiatry of phenothiazine of central elective action (4560 RP).] Ann Med Psychol (Paris) 110:112-117, 1952

19. Feld M: A propos de la communication de M. P. Menger (séance du 22 novembre 1954), sur une intervention préfrontale à la portée et du ressort électif du psychiatre. Ann Med Psychol (Paris) 113:250-251, 1955

20. Ferdière G: Résultats immédiats de la leucotomie préfrontale dans un cas de schizophrénie avec stupeur catatonique. Ann Med Psychol (Paris) I:81-89, 1940

21. Fineberg NA, Reghunandanan S, Simpson HB, Phillips KA, Richter MA, Matthews K, et al: Obsessive-compulsive disorder (OCD): Practical strategies for pharmacological and somatic treatment in adults. Psychiatry Res 227:114-125, 2015

22. Gross D, Schäfer G: Egas Moniz (1874-1955) and the "invention" of modern psychosurgery: a historical and ethical reanalysis under special consideration of Portuguese original sources. Neurosurg Focus 30(2):E8, 2011

23. Guillemain H: Chronique de la psychiatrie ordinaire. Patients, soignants et institutions en Sarthe du XIXe au XXIe siècle. Le Mans: Les éditions de la Reinette, 2010

24. Houdart R: [Eulogy of Marcel David (1898-1986).] Bull Acad Natl Med 172:241-249, 1988 (Fr)

25. Jaubert A: L'excision de la pierre de folie. Autrement 4:2266, 1975-1976

26. Kunz E: Henri Laborit and the inhibition of action. Dialogues Clin Neurosci 16:113-117, 2014

27. Le Beau J: Psycho-chirurgie et fonctions mentales: techniques, résultats, applications physiologiques. Paris: Masson, 1954

28. Le Jeune F, Vérin M, N'Diaye K, Drapier D, Leray E, Du Montcel ST, et al: Decrease of prefrontal metabolism after subthalamic stimulation in obsessive-compulsive disorder: a positron emission tomography study. Biol Psychiatry 68:1016-1022, 2010

29. Mallet L, Polosan M, Jaafari N, Baup N, Welter ML, Fontaine D, et al: Subthalamic nucleus stimulation in severe obsessive-compulsive disorder. N Engl J Med 359:2121-2134, 2008

30. Mazoyer B: In memoriam: Jean Talairach (1911-2007): a life in stereotaxy. Hum Brain Mapp 29:250-252, 2008

31. Menger P, Begard P: Une intervention préfrontale à la portée et du ressort électif du psychiatre. Ann Med Psychol (Paris) 112:757-761, 1954 
32. Missa JN: La psychochirurgie: histoire d'une pratique expérimentale. Partie I: L'époque des pionniers (1935-1954). Med Sci (Paris) 13:1370-1374, 1997

33. Missa JN: La psychochirurgie: histoire d'une pratique expérimentale. Partie II: Les nouvelles techniques de chirurgie stéréotaxique (1955-1997). Med Sci (Paris) 13:1521-1524, 1997

34. Moniz E: Tentatives opératoires dans le traitement de certaines psychoses. Paris: Masson, 1936

35. Nobel Foundation: Egas Moniz - biographical. Nobelprize. org. (https://www.nobelprize.org/nobel_prizes/medicine/ laureates/1949/moniz-bio.html) [Accessed July 12, 2017]

36. Nuttin B, Cosyns P, Demeulemeester H, Gybels J, Meyerson B: Electrical stimulation in anterior limbs of internal capsules in patients with obsessive-compulsive disorder. Lancet 354:1526, 1999

37. Polosan M, Millet B, Bougerol T, Olié JP, Devaux B: Traitement psychochirurgical des TOC malins: à propos de trois cas. Encephale 29:545-552, 2003

38. Pressel DM: Nuremberg and Tuskegee: lessons for contemporary American medicine. J Natl Med Assoc 95:1216-1225, 2003

39. Pressman JD: Last Resort: Psychosurgery and the Limits of Medicine. Cambridge, UK: Cambridge University Press, 2002

40. Puech P: De l'intérêt d'une liaison entre neuro-psychiatrie et neurochirurgie. Paris: Masson, 1941

41. Puech P, Guilly P, Lairy-Bounes GC, Guilly P, Baudouin A: Introduction à la psycho-chirurgie. Paris: Masson, 1950

42. Robison RA, Taghva A, Liu CY, Apuzzo MLJ: Surgery of the mind, mood, and conscious state: an idea in evolution. World Neurosurg 77:662-686, 2012

43. Ryan KJ, Brady JV, Lebacqz K, Cooke RE, Louisell DW, Height DI, et al: Psychosurgery: Report and Recommendations. Washington, DC: National Commission for the Protection of Human Subjects of Biomedical and Behavioral Research, 1977

44. Talairach J: Souvenirs des études stéréotaxiques du cerveau humain: Une vie, une équipe, une méthodologie: L'Ecole de Sainte-Anne. Montrouge, France: John Libbey Eurotext, 2007

45. Talairach J, Hécaen H, David M: Lobotomie préfrontale limitée par électrocoagulation des fibres thalamo-frontales a leur émergence du bras antérieur de la capsule interne. Rev Neurol 83:59, 1949

46. Talairach J, Morel P: Psychochirurgie. Encycl Méd Chir 37830-A:10-17, 1963

47. Talairach J, Tournoux P: Co-Planar Stereotaxic Atlas of the Human Brain: 3-Dimensional Proportional System: An Approach to Cerebral Imaging. Stuttgart: Thieme, 1988
48. Talairach J, Tournoux P: Referentially Oriented Cerebral MRI Anatomy: An Atlas of Stereotaxic Anatomical Correlations for Gray and White Matter. Stuttgart: Thieme, 1993

49. Tierney TS, Abd-El-Barr MM, Stanford AD, Foote KD, Okun MS: Deep brain stimulation and ablation for obsessive compulsive disorder: evolution of contemporary indications, targets and techniques. Int J Neurosci 124:394-402, 2014

50. Welter ML, Burbaud P, Fernandez-Vidal S, Bardinet E, Coste $\mathrm{J}$, Piallat B, et al: Basal ganglia dysfunction in OCD: subthalamic neuronal activity correlates with symptoms severity and predicts high-frequency stimulation efficacy. Transl Psychiatry 1:e5, 2011

51. Wilson K: Occasional notes: Second International Neurological Congress, London, 1935. J Neurol Psychopathol 15:283-288, 1935

52. Zanello M, Decofour M, Corns R, Pallud J, Charlier P: Report of a successful human trepanation from the Dark Ages of neurosurgery in Europe. Acta Neurochir (Wien) 157:303-304, 2015

\section{Disclosures}

The authors report no conflict of interest concerning the materials or methods used in this study or the findings specified in this paper.

\section{Author Contributions}

Conception and design: Zanello, Pallud. Acquisition of data: Zanello. Analysis and interpretation of data: Zanello, Pallud. Drafting the article: Zanello, Pallud, Peeters, Turak, Krebs, Oppenheim, Gaillard, Devaux. Critically revising the article: Zanello, Pallud, Peeters, Turak, Krebs, Oppenheim, Gaillard, Devaux. Reviewed submitted version of manuscript: Zanello, Pallud, Peeters, Turak, Krebs, Oppenheim, Gaillard, Devaux. Approved the final version of the manuscript on behalf of all authors: Zanello. Statistical analysis: Zanello, Pallud. Administrative/technical/material support: Pallud, Baup. Study supervision: Pallud, Krebs, Oppenheim, Gaillard, Devaux.

\section{Supplemental Information Videos}

Video Abstract. https://vimeo.com/227069042.

\section{Correspondence}

Marc Zanello, Neurosurgery Department, Sainte-Anne Hospital, 1 rue Cabanis, Paris 75014, France. email: marc.zanello@orange.fr. 